\title{
Replacement Model for Higher Education Institution Hostel Building Maintenance in Malaysia
}

\author{
Yuseni Ab Wahab, Abd Samad Hasan Basari, and Burairah Hussin
}

\begin{abstract}
This paper is part of an on-going research on the development of maintenance management cost model for Higher Education Institution Hostel Buildings in Malaysia where the case study is conducted at Kolej Universiti Islam Melaka (KUIM). The model is developed to analyse the total cost curve for various values of the uncertain parameter, and noting the effect of this variation on the optimal solution. The decision areas addressed based on the replacement action that are assumed to be known with certainty. This is due to the item is not subject to failure but consider the operating cost with use. The study is aimed to assist engineers in deciding an appropriate replacement policy. This is usually useful to plot the total cost per unit time curve. The advantage of the curve is that, along with giving the optimal value, it shows the total cost around the optimum. If the curve is fairly flat around the optimum, it is not really very important that engineers should plan for the replacements exactly at the optimum. The model is proposed to guide and facilitate when dealing with optimization problems. If there is uncertainty about the value of the particular parameter required during the analysis, then the replacement cost is unsure. Furthermore the evaluation of the total cost curve for various values of the uncertain parameter could in consequence affect the optimal solution.
\end{abstract}

Index Terms-Hostel building maintenance, replacement model, replacement cost.

\section{INTRODUCTION}

Some equipment operates with excellent efficiency when it is new. But as it ages, the performance deteriorates. An example is the Door components in Kolej Universiti Islam Melaka (KUIM) hostel building. When new, it is considered as the equipment is in good condition. However if there has a small crack, it will affect the quality of the Door [1]-[3]. Is it economically justifiable to repair or replace the Door, thus reducing the operating cost of the Hostel building? In general, replacements will cost money in terms of component and a balance is required between the money spent for replacements and savings obtained to reduce the operating cost. Thus, this study aimed to determine an optimal replacement policy that will minimize the sum of operating and replacement costs per unit time [4], [5]. The goal of this research is to present model that can be used to optimize component replacement decision. The interest in

Manuscript received May 3, 2014; revised July 12, 2014.

Yuseni Ab Wahab is with Kolej Universiti Islam Melaka, Malaysia (email: yuseni@kuim.edu.my).

Abd Samad Hasan Basari was with Universiti Teknikal Malaysia Melaka.

Burairah Hussin is with University Technology Malaysia Melaka (UTeM). this decision area is because a common approach to improving the reliability of the system or complex equipment is through preventive replacement of critical component within the system. Thus it is necessary to be able to identify which component should be considered for preventive replacement and which should be left to run until they fail. If the component is a candidate for preventive replacement, then the subsequent question to be answered is: What is the best time? The primary goal; addressed in this chapter is that to making a system more reliable through preventive replacement [2].

Replacement problem (and maintenance problem in general) can be classed as either deterministic or probabilistic (stochastic).

Deterministic problem are those in which the timing and out came of the replacement action are assumed to be know with certainty. For example we may have an item that is not subject to failure but whose operating cost increases with use [3]. To reduce this operating cost, a replacement can be performed. After the replacement the trend in operation cost. Example of component replacement problem that can be treated with a deterministic model. Probabilistic problem are those where the timing and outcome of the replacement action depend on chance. In the simplest situation the equipment may be described as being good or failed. The probability law describing changes from good to failed may be described by the distribution of time between completion failure is a random variable whose distribution may be termed the equipment's failure distribution [4].

\section{OPTIMAL REPLACEMENT TIME FOR COMPONENT/EQUPMENT}

Some component/equipment operates with excellent efficiency when it's is new, but as it ages its performance deteriorates, when on the increasing cost trend is it economically justifiable to replace the equipment. In general replacement cost money in term of material and wages and balance is required between the money spent on replacement and saving obtained by reducing the operating cost. Thus, to determine an optimal replacement policy that will minimize the sum of operating and replacement cost per unit time [3].

When dealing with optimization problem, in general, we wish to optimize some measure of performance over a long period. This is equivalent to optimizing the measure of performance per unit. This approach is easier to deal with mathematically when compare to developing a model for optimizing a measure of performance over a finite horizon [4].

The cost conflict and associated optimization problem. It 
should be stressed that this class of problem can be termed short term deterministic since the magnitude of the interval between replacement is weeks or month, rather than years .If the interval between replacement was measured in years, then the fact that money changes in value over time would need to be taken into account in the analysis. Such problem can be term replacement [5].

\section{Stochastic Preventive RePlacement}

Before proceeding with the development of component replacement models, It is important to note that preventive replacement action that is actions taken before equipment reaches a failed state. Require two necessary conditions:

1) The total cost of the replacement must be greater after failure than before (if cost the appropriate criterion, otherwise an appropriate criterion such as downtime is substituted in place of cost)This may be caused by a greater loss of production since replacement after failure is unplanned or failure of one piece of plant may cause damage to other equipment.

2) The hazard rate of the equipment must be increasing. To Illustrate this point, we may consider equipment with a constant hazard rate That is failures occur according to the negative exponential distribution or equivalent the Weibull distribution, Where the shape parameter $\beta=1.0$. When this is the case, replacement before failure does not affect the probability that the equipment will fail in the next instant, given that it is good now. Consequently, money and time are wasted if preventive replacement is applied to equipment that fails according to the negative exponential distribution. Obviously, when equipment fails according to the hyper exponential distribution or the Weibull whose $\beta$ value is less than 1.0 . Its hazard rate is decreasing and again component preventive replacement should not be applied. Examples of component where a decreasing hazard rate has been identified include quartz crystals, medium - and high quality resistors and capacitors and solid - state device such as semiconductors and integrated circuits.

\section{OPtimal PREVEnTIVE REPlacement}

An item, sometimes termed a line replaceable unit or part, is subject to sudden failure and when failure occurs, the item has to be replaced. Since failure is unexpected. It is not unreasonable to assume that failure replacement is more costly than a preventive replacement [6]. For example, a preventive replacement is planned and arrangements are made to perform it without unnecessary delays, or perhaps a failure may cause damage to other equipment. In order to reduce the number of failure, preventive replacement can be scheduled to occur at specified intervals. However, a balance is required between the amount spent on the preventive replacement and their resulting benefits, that is reduced failure replacements [7]. The conflicting cost consequences and their resolution by identifying the total cost curve. The replacement policy is one where preventive replacement occur at fixed intervals of time, failure replacement occur whenever necessary and to determine the optimal interval between the preventive replacement to minimize the total expected cost of replacing the equipment per unit time[8].

\section{Model COnStruction}

When dealing with optimization problems, in general, this study aimed to optimize some measure of performance over a long period. In many situations, this is equivalent to optimize the measure of performance per unit time [6], [7]. This approach is easier to formulate mathematically when compared to develop a model in optimizing a measure of performance over a finite horizon [8]-[12].

The model construction is as follows.

\section{Construction of Model:}

1. $c(t)$ is the operating cost per unit time at time $t$ after replacement

\section{2. $C$, is the total cost of a replacement.}

3. The replacement policy /to perform replacements at interval length

4. The objective is to determine the optimal interval between replacements to minimize the total cost of operation and replacement per time

The total cost per unit $C(t)$ for replacement at time $t .$. , is

$C(t)=$ total cost in interval $(0, t)$ length of interval

To use the equation $\mathrm{c}\left(t_{r}\right)=\mathrm{C}\left(t_{r}\right)$, it requires that the trend in operating costs be an increasing function, which in practice is a very reasonable assumption. In practice, it is often not unreasonable to disregard the replacement time since it is usually small when compared to the interval between the replacements [8]-[10]. Any costs, such as production losses incurred due to the duration of the replacement, need to be incorporated into the cost of the replacement action. Otherwise, a numerical solution is required as in (1):

$$
C\left(t_{r}\right)=\frac{\int_{0}^{t_{r}} c(t) d t+C_{r}}{t_{r+T_{r}}}
$$

Models are developed whereby, for particular assumptions, the optimal interval between the replacements can be obtained. In practice, there may consider difficulty in scheduling replacements to occur at their optimal time, or in obtaining the values of some of the parameters required for the analysis [11].

\section{RESULT AND DisCUSSION}

The Hostel building maintenance data is gathered from 
Kolej Universiti Islam Melaka (KUIM) in certain period of time. By using Eq. (1), in discrete form, Table I is obtained from which it is seen that the optimal replacement age is 10 months, and the associated cost per month is MYR 17.14 This table also show the deterioration trend from month 1 to 10 and increase again from 11 to 12 .The associated graph of cost per month versus time is provided in Fig. 1, which includes the calculation of the optimizing criterion $c(t)=$ $\mathrm{C}\left(f_{r}\right)$ when the trend in operating cost is discretized. Therefore, by replacing at the end of month 10 , since next period's do operations and maintenance cost, $c(t=10)$, is greater than the average cost to date (MYR 17.14).

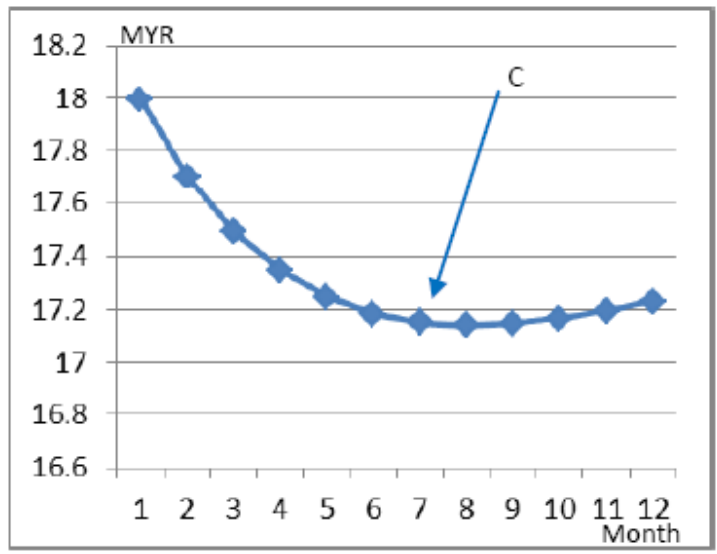

Fig. 1. Replacement cost for door.

TABLE I: REPLACEMENT COST FOR DOOR

\begin{tabular}{|c|c|}
\hline Month & MYR \\
\hline 1 & 17.99 \\
\hline 2 & 17.7 \\
\hline 3 & 17.49 \\
\hline 4 & 17.34 \\
\hline 5 & 17.24 \\
\hline 6 & 17.18 \\
\hline 7 & 17.15 \\
\hline 8 & 17.16 \\
\hline 9 & 17.18 \\
\hline 10 & 17.14 \\
\hline 11 & 17.19 \\
\hline 12 & 17.23 \\
\hline *MYR- Malaysia Ringgit
\end{tabular}

\section{A. Sample Numerical Solution}

The simplified formula after referring to Eq. (1) is:

$$
\begin{aligned}
& \mathrm{C}(\operatorname{tr})=(1 / t) *(((600.44 / 30) * t+((22172.94 / 30) \\
& * \operatorname{EXP}(-\mathrm{X} *(t)) / \mathrm{X})-((600.44 / 30) / \mathrm{X})+(200) / 30))
\end{aligned}
$$

where $t=24$ hours (1 Day), and X = Exponent $/$ days

$$
\begin{gathered}
X=5,357 / 30 \text { days }=0.178567=(1 / 24) *(((600.44 / 30) * \\
24+((22172.94 / 30)
\end{gathered}
$$

$\left.\left.\left.* \operatorname{EXP}\left(-\mathrm{X}^{*}(24)\right) / \mathrm{X}\right)-((600.44 / 30) / \mathrm{X})+(200) / 30\right)\right)=17.99$
Another critical component in the hostel building is Lamp. Table II show the replacement cost for Lamp.

TABLE II: REPLACEMENT COST FOR LAMP
\begin{tabular}{|c|c|}
\hline Month & MYR \\
\hline 1 & 18.92 \\
\hline 2 & 18.39 \\
\hline 3 & 17.99 \\
\hline 4 & 17.7 \\
\hline 5 & 17.49 \\
\hline 6 & 17.34 \\
\hline 7 & 17.24 \\
\hline 8 & 17.18 \\
\hline 9 & 17.15 \\
\hline 10 & 17.14 \\
\hline 11 & 17.14 \\
\hline 12 & 17.16 \\
\hline *MYR- Malaysia Ringgit
\end{tabular}

\section{B. Sample Numerical Solution}

The simplified formula after referring to Equation (1.1) is:

$$
\begin{aligned}
& \mathrm{C}(\operatorname{tr})=((1 / t) *(((400.44 / 30) * t+((22172.94 / 30) \\
& \left.\left.\left.* \operatorname{EXP}\left(-\mathrm{X}^{*}(t)\right) / \mathrm{X}\right)-((400.44 / 30) / \mathrm{X})+(200) / 30\right)\right)
\end{aligned}
$$

where $\mathrm{t}=24$ hours $(1$ Day $)$, and $\mathrm{X}=$ Exponent $/$ days

$$
\begin{gathered}
\mathrm{X}=5,357 / 30 \text { days }=0.178567=(1 / 22) *(((400.44 / 30) * 22+ \\
((22172.94 / 30) \\
\left.\left.\left.* \operatorname{EXP}\left(-\mathrm{X}^{*}(22)\right) / \mathrm{X}\right)-((400.44 / 30) / \mathrm{X})+(200) / 30\right)\right)=18.92
\end{gathered}
$$

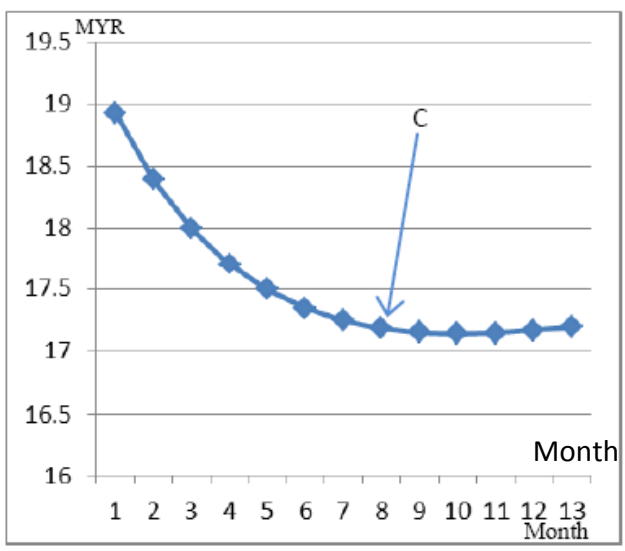

Fig. 2. Replacement cost for lamp.

Lamp operating cost is RM18.92 for first month and by using Eq. (1), in discrete form, the data is obtained in Table II, from which it is seen that the optimal replacement age is 11 months, and the associated cost per month is MYR17.14. The associated graph of cost per month versus time is provided in Fig. 2, which includes the calculation of the optimizing criterion $c(t)=\mathrm{C}(f r)$ when the trend in operating cost is discretized. Therefore by replacing at the end of 
month 11, since next period is doing operation and maintenance cost, $c(t=11)$, the replacement cost is greater than the average cost to date (MYR 17.14).

Another critical component in the hostel building is sink. Table III show the replacement cost for sink.

TABLE III: REPLACEMENT COST FOR SINK
\begin{tabular}{|l|l|}
\hline Month & MYR \\
\hline 1 & 17.8 \\
\hline 2 & 17.6 \\
\hline 3 & 17.4 \\
\hline 4 & 17.3 \\
\hline 5 & 17.2 \\
\hline 6 & 17.15 \\
\hline 7 & 17.13 \\
\hline 8 & 17.1 \\
\hline 9 & 17.15 \\
\hline 10 & 17.13 \\
\hline 11 & 17.16 \\
\hline 12 & 17.2 \\
\hline \multirow{2}{*}{$*$ MYR- Malaysia Ring } \\
\hline
\end{tabular}

\section{Sample Numerical Solution}

The simplified formula after referring to Eq. (1) is:

$$
\begin{aligned}
& \mathrm{C}(t r)=(1 / t)^{*}(((600.41 / 30) * t+((22172.94 / 30) \\
& \left.\left.\left.* \operatorname{EXP}\left(-\mathrm{X}^{*}(t)\right) / \mathrm{X}\right)-((600.44 / 30) / \mathrm{X})+(200) / 30\right)\right)
\end{aligned}
$$

where $t=24$ hours (1 Day), and X = Exponent $/$ days

$$
\begin{gathered}
\mathrm{X}=5,357 / 30 \text { days }=0.178567 \\
=(1 / 24) *(((600.41 / 30) * 24+((22172.94 / 30) \\
* \operatorname{EXP}(-\mathrm{X} *(24)) / \mathrm{X})-((600.41 / 30) / \mathrm{X})+(200) / 30)) \\
=17.8
\end{gathered}
$$

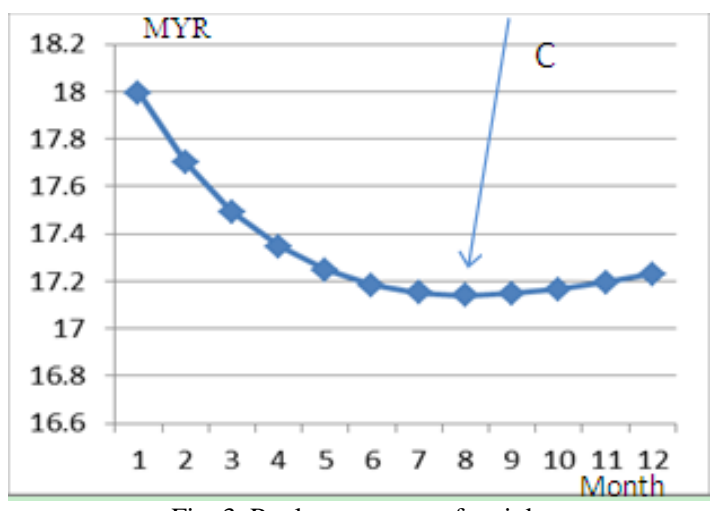

Fig. 3. Replacement cost for sink.

Sink operating cost is RM17.8 for first month and by using Eq. (1), in discrete form, the data is obtained in Table III, from which it is seen that the optimal replacement age is 8 months, and the associated cost per month is MYR17.1 The associated graph of cost per month versus time is provided in Fig. 3, which includes the calculation of the optimizing criterion $c(t)=\mathrm{C}(f r)$ when the trend in operating cost is discretized. Therefore by replacing at the end of month 8 , since next period is doing operation and maintenance cost, $c(t=8)$, the replacement cost is greater than the average cost to date (MYR 17.1).

\section{CONCLUSION AND FutURE RESEARCH}

The hostel building maintenance model is show that total cost curve is not fairly flat around the optimum rising rapidly on both sides. This is then the optimal interval should be adhered to all possible circumstances. If there is uncertainty about the value of the particular parameter required in the analysis [9]-[12], then the evaluation of the total cost curve for various values of uncertain parameter, could affect the optimal solution. In order to further assist engineers in deciding what appropriate replacement policy should be, it is useful to plot the total cost per unit time curve. The advantage of the curve is that, along with giving the optimal value of $t$, it shows the form of the total cost around the optimum value [8]. If the curve is fairly flat around the optimum, it is not really very important that engineers should plan for the replacements to achieve the optimum value, thus giving some leeway in scheduling the work [11], [12].

The goal was to develop a model that related inspection frequency too profit. The way in which the model was developed is such that had the goal been to establish the optimal inspection frequency to minimize total cost, then the same result would have been obtained. The most important point from this problem is that it is concerned with identifying the best level of preventive maintenance (in the inspections and replacement) when the failure rate of equipment is constant. When necessary the replacement duration can be incorporated into the replacement model, as is required when the goal is the minimization of total downtime or equivalent, the maximization of item availability. This research has presented a model that can used to establish the optimal time based discard decision if the goal is a constant - interval preventive replacement policy [12]

For future improvement, the model can be hybridizing technique with Artificial Intelligent (AI) and data mining to increase its accuracy.

\section{ACKNOWLEDGEMENTS}

This research is supported by Kolej Universiti Islam Melaka (KUIM) include overall sponsored for ICMTS 2014. This research is part of Degree of Doctor of Philosophy $(\mathrm{PhD})$ in the Faculty Information and Communication Technology, Universiti Teknikal Malaysia Melaka (UTeM).

\section{REFERENCES}

[1] Y. A. Wahab and A. S. H. Basari, "Building maintenance management preliminary finding of a case study in ICYM," Middle-East Journal of Scientific Research, vol. 17, no. 9, pp. 1260-1268, 2013.

[2] Y. A. Wahab and A. S. H. Basari, "Analysis of down time and reliability estimation in hostel building maintenance-a case study," Middle-East Journal of Scientific Research, 2013.

[3] A. S. H. Basari, "Maintenance modeling tools with special to incomplete data," PhD Thesis, Universiti Teknikal Malaysia Melaka (UTeM), Malaysia, 2009.

[4] A. K. S. Jardine and A. H. C. Tsang, "Maintenance, replacement and reliability," 2006 CRC Press Mechanical Engineering, A Series of Textbooks and Reference Book, pp. 57-97, 2006.

[5] R. P. Nicola and R. Dekker, "Optimal maintenance of multicomponent systems: A review," in Complex System Maintenance 
Handbook, D. N. P. Murthy, A. K. S. Kobbacy, Eds. Amsterdam: Springer ch. 7, 2008.

[6] B. Jones, I. Jenkinson, and J. Wang, "Methodology of using delay time analysis for a manufacturing industry," Reliability Engineering \& System Safety, vol. 94, no. 1, pp. 111-124, 2009.

[7] W. B. Wang, D. Banjevic, and M. Pecht, "A multi-component and multi-failure mode inspection model based on the delay time concept," Reliability Engineering \& System Safety, vol. 95, no. 8, pp. 912-920, 2010.

[8] W. B. Wang, "Delay time modeling," in Complex System Maintenance Handbook, D. N. P. Murthy and A. K. S. Kobbacy, Eds. Amsterdam: Springer, pp. 345-70, 2008.

[9] A. A. L. Olanrewaju, "Case for Quantitative analysis of defects in university building: User perspective," Journal Build Environment Project and Asset Management, vol. 2, no. 2. pp. 167-181, 2012.

[10] A. A. L. Olanrewaju, "Case for alternative approach to building maintenance management of public universities," Journal of Building Appraisal, vol. 5, pp. 201-212, 2010.

[11] O. K. Chuan, "The minister of housing and local government," Call for Check on Buildings: Architects push for Malaysia Inspection Every Five Years, The Star, 9th May, 2008, pp. 33.

[12] N. A. J. Hastings, "Component reliability, replacement and cost analysis with incomplete failure data," in Case Studies in Reliability and Maintenance, W. R. Blischke and D. N. P. Murthy, Eds. New York: Wile, 2004.

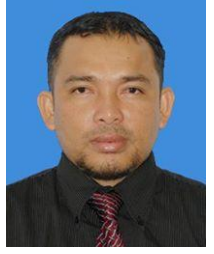

Yuseni Bin Ab Wahab is a lecturer at the Kolej Universiti Islam Melaka (KUIM)). His areas of research include industrial maintenance engineering, building maintenance system, hostel maintenance management system and $\mathrm{AI}$ application, decision support technology. He has published 5 research papers in Journal and Conferences.

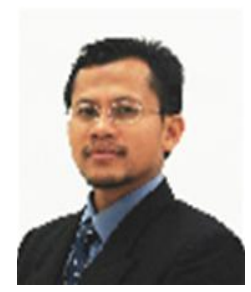

Abd Samad Hasan Basari received the B.S degree in mathematics from Universiti Kebangsaan Malaysia in 1998 and the M.Sc degree in ITeducation from Universiti Teknologi Malaysia in 2004. He obtained his $\mathrm{PhD}$ degree on ICT (Maintenance Modelling Tools) at Universiti Teknikal Malaysia Melaka in 2009. His research interests are in AI application, decision support technology and modeling.

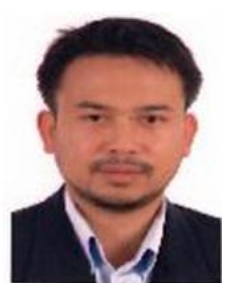

Burairah Hussin got a $\mathrm{PhD}$ degree in management science - condition monitoring modeling from University of Salford, UK in 2007. He is currently working as an associate professor in University Technology Malaysia Melaka (UTeM) and. His research interests are in data analysis, data mining, maintenance modeling, artificial intelligent. 